\title{
Analysis of Diarrhetic Shellfish Toxins in Mussels from the Adriatic Coast of Italy
}

\author{
Jiaping Zhao, ${ }^{* 1}$ Giampaolo Cenci, ${ }^{* 2}$ Eraldo Di Antonio, ${ }^{* 2}$ and Takeshi Yasumoto*1 \\ ${ }^{* 1}$ Faculty of Agriculture, Tohoku University, Tsutsumidori Amamiya, Aoba, Sendai, Miyagi 981, Japan \\ *2 Istituto di Ispezione degli Alimenti di Origine Animale, Facolta di Veterinaria, Universita di Perugia, Via S. Costanzo, \\ 06126 Perugia, Italy
}

(Received April 11, 1994)

\begin{abstract}
Diarrhetic shellfish toxins in mussels collected from the Adriatic coast of Italy were analyzed by both mouse bioassay and fluorometric high performance liquid chromatography (HPLC). Of eleven specimens tested, one each from Trieste, Rimini, and Ancona proved to be toxic in the mouse bioassay. In each case, okadaic acid was confirmed as the major toxin by HPLC analysis, but in addition to okadaic acid, unprecedented toxins having cytotoxic activity were found to be present in a Rimini sample.
\end{abstract} toxin

Key words: DSP, Italy, Adriatic Sea, HPLC, okadaic acid, new toxins, mussel, diarrhetic shellfish

Incidents of diarrhetic shellfish poisoning (DSP) have dramatically increased in both frequency and geographical distribution in recent years. ${ }^{1)}$ In addition to the health risks, the economic damage caused by frequent closures of farms poses a serious problem to local communities. To alleviate these health and economic problems, monitoring programs on shellish toxicity are being implemented in many places usign bioassays with mice. ${ }^{2)}$ Besides the ethical problem of using an animal bioassay, the method has a drawback of not distinguishing three different groups of toxins implicated in DSP (DS-toxins, Fig. 1); namely, the okadaic acid (OA) group, the pectenotoxin group (PTXs), and yessotoxin

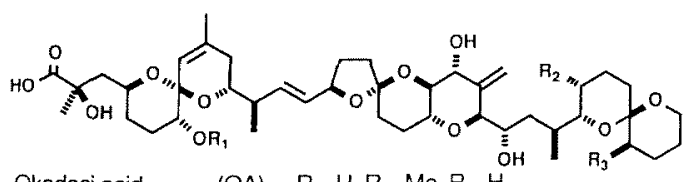

$$
\text { Okadaci acid }
$$$$
\text { (OA) } \mathrm{R}_{1}=\mathrm{H}, \mathrm{R}_{2}=\mathrm{Me}, \mathrm{R}_{3}=\mathrm{H}
$$

Dinophysistoxin-1 (DTX1) $\mathrm{R}_{1}=\mathrm{H}, \mathrm{R}_{2}=\mathrm{Me}, \mathrm{R}_{3}=\mathrm{Me}$

Dinophysistoxin-2 (DTX2) $\mathrm{R}_{1}=\mathrm{H}, \mathrm{R}_{2}=\mathrm{H}, \mathrm{R}_{3}=\mathrm{Me}$

$\begin{array}{ll}\text { Dinophysistoxin-2 (DTX2) } & R_{1}=H, R_{2}=H, R_{3}=M e \\ \text { Dinophysistoxin-3 (DTX3) } & R_{1}=\text { acyl, } R_{2}=M e, R_{3}=M e\end{array}$
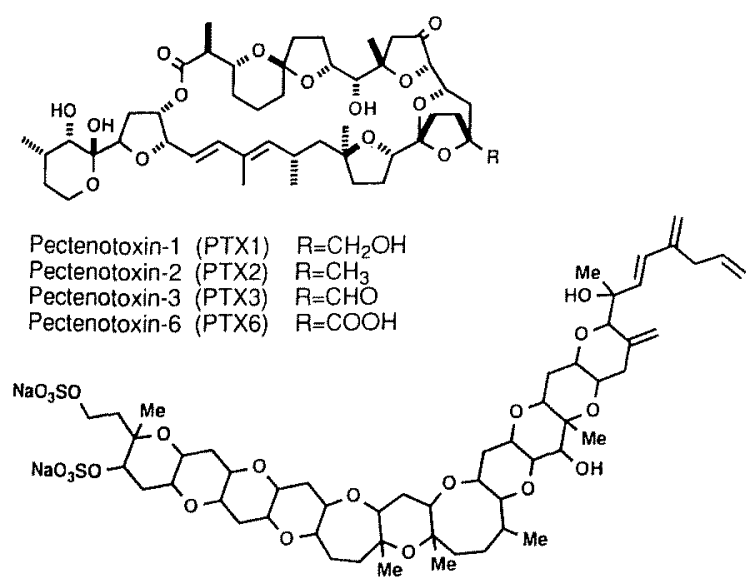

yessotoxin (YTX)
(YTX). ${ }^{3)}$ As the toxins differ not only in chemical structure but also in toxicological effects, elucidation of toxin profiles by instrumental analyses is indispensable for evaluation of the health risks. Of these toxins, OA and dinophysistoxin-1 (DTX1) are considered to be more important than others because of their potent diarrheagenicity ${ }^{4,5}$ and tumor promoting activity. $\left.{ }^{6}\right)$ Both OA and DTX1 can be determined by fluorometric high performance liquid chromatography (HPLC). ${ }^{7}$

In the Adriatic Sea, DSP outbreaks have been known only recently. ${ }^{8-10)}$ Toxicity was tested chiefly by mouse bioassays or by an ELISA method, necessitating further confirmation by HPLC analyses. In the present paper we report confirmation of $\mathrm{OA}$ in mussels from Trieste, Rimini, and Ancona, and occurrence of unprecedented toxins in one specimen from Rimini.

\section{Materials and Methods}

\section{Materials}

Mussels Mytilus falloprovincialis were collected in 1990 at Trieste, Goro, Rimini, Ancona, and Pescara (Fig. 2). Dates of the collection are shown in Table 1. The hepatopancreas which comprised 13 to $17 \%$ of the whole meat was removed from other tissues. Ten grams of the hepatopancreas was used for analysis.

\section{Mouse Bioassays}

Lethal potencies of acetone extracts of hepatopancreas were determined by a mouse bioassay method. ${ }^{2}$ The method expresses toxicity by a mouse unit (MU), which is defined as the amount of a toxin, or toxins, to kill a male mouse of ddY strain of $20 \mathrm{~g}$ body weight in $24 \mathrm{~h}$. The amounts of OA, DTX1, and PTX6 equivalent to one MU are 4.0, 3.2, and $10.0 \mu \mathrm{g}$, respectively. ${ }^{3)}$

\section{HPLC Analysis}

Toxins were esterified with 9-anthryldiazomethane (ADAM) as described previously. ${ }^{7)}$ The resultant fluorescent esters were chromatographed first on a Develosil ODS-7 column $(4.6 \times 250 \mathrm{~mm})$ with acetonitrile-methanol-water $(8: 1: 1)$. Fluorescent peaks whose retention times agreed with or were close to those of the reference toxins were collected from the outlet of the fluoromonitor and re-chromatographed on a second column (Capcell pak CN SG120, $4.6 \times 250 \mathrm{~mm}$ ) with acetonitrile-water $(53: 47)$ for further confirmation.

Fig. 1. Structures of diarrhetic shellfish toxins. 
Tests for PTXs and YTX

The possible occurrence of PTXs and YTX in the Rimini sample was tested by a method previously described for the purification of DS-toxins. ${ }^{11}$ Methanol extracts of the hepatopancreas were first separated into neutral and acidic fractions on an alumina column. Each fraction, afteer being tested by mouse bioassays, was further purified by columns of silica gel (Merck) and then $C_{18}$ bonded silic (ODS-Q3, Fuji gel) chromatography. The toxic fraction thus obtained was tested for the presence of YTX by thin layer chromatography (TLC) on a silica gel 60 plate (Merck) with chloroform-methanol-water $(50: 10: 1){ }^{11}$

\section{Purification of New Toxins}

Lyophilized powder $(13.8 \mathrm{~g})$ prepared from the hepatopancreas of mussels collected at Rimini on July 9, 1990 was extracted with methanol, and the toxic extract purified over columns of alumina, silica gel, and ODS-Q3, as described previously. ${ }^{11}$ Final purification was carried out on a Develosil ODS-5 column (Nomura Chemicals) with methanol-0.1\% acetic acid $(8: 2)$. The flow rate was kept at $1.0 \mathrm{~m} / / \mathrm{min}$. Four toxic fractions found to be lethal to mice were collected. Individual toxic fractions were further purified on the Develosil ODS- 5 column under the same conditions. Elution of toxins was monitored by mouse bioassays during the early stages of purification and with a UV-detector (at $205 \mathrm{~nm}$ ) at the final stage.

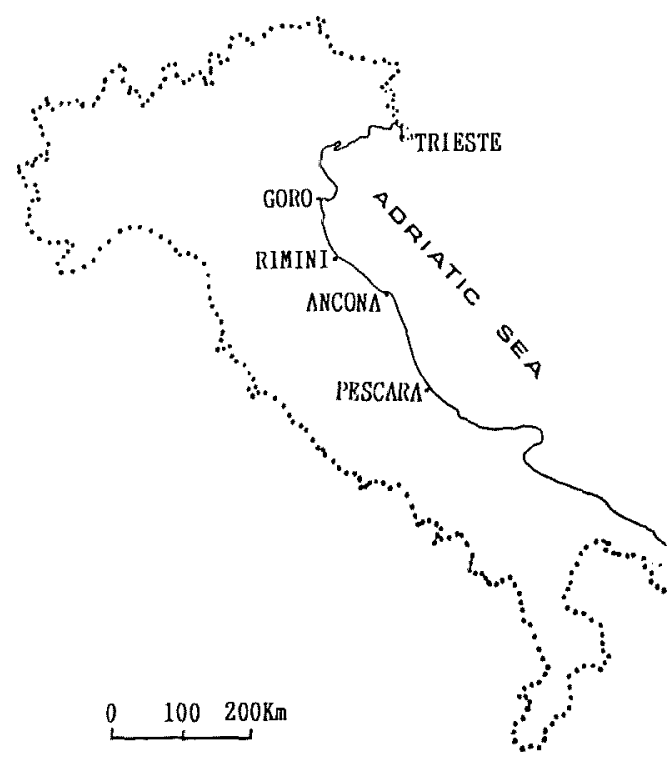

Fig. 2. Sites of mussel collection.

Table 1. Results of mouse bioassays and fuorometric HPLC analyses of mussels collected from the Adriatic Coasts of Italy in 1990

\begin{tabular}{llcc}
\hline $\begin{array}{c}\text { Sampling } \\
\text { sites }\end{array}$ & Date & $\begin{array}{c}\text { Bioassay results } \\
\text { (MU/g) }\end{array}$ & $\begin{array}{c}\text { OA by HPLC* } \\
\mu \mathrm{g} / \mathrm{g}(\mathrm{MU} / \mathrm{g})\end{array}$ \\
\hline Trieste & July 27 & $0.5-1.0$ & $3.2(0.8)$ \\
Goro & June 11 & $<0.5$ & $\mathrm{ND}$ \\
& July 26 & $<0.5$ & $\mathrm{ND}$ \\
& Sep. 3 & $<0.5$ & $\mathrm{ND}$ \\
Rimini & June 9 & $2.0-3.0$ & $3.3(0.8)$ \\
& July 24 & $<0.5$ & $\mathrm{ND}$ \\
Ancona & June 19 & $<0.5$ & $\mathrm{ND}$ \\
& July 13 & $0.5-1.0$ & $1.4(0.4)$ \\
& Sep. 4 & $<0.5$ & $\mathrm{ND}$ \\
Pescara & May 15 & $<0.5$ & $\mathrm{ND}$ \\
& July 23 & $<0.5$ & ND \\
\hline
\end{tabular}

DTXI was not detected in all samples.

* ND denotes not detected.
Cytotoxicity Tests

Test samples were prepared by suspending $2 \mu \mathrm{g}$ of individual toxin in $1 \mathrm{ml}$ of a culture medium (PRMI-FBS antibiotics, 10:1:0.1, Flow Laboratories Co.). Murine leukemia cells (P388) were grown in the same culture medium at $37^{\circ} \mathrm{C}$ in an atmosphere enriched in $\mathrm{CO}_{2}(5 \%)$, and cell density was adjusted to $5 \times 10^{5} / \mathrm{ml}$. A $5 \mathrm{mg} / \mathrm{ml}$ solution of $3-(4,5-$ dimethylthiazol-2-yl)-2,5-diphenyl-2H-tetrazolium bromide (MTT, Dojin Co.) was prepared by dissolving MTT in a phosphate buffer $(7.5 \mathrm{mM}, \mathrm{pH}$ $7.1)$. For bioassay 96 well plates were seeded with $4.5 \times 10^{4}$ cells per well in $90 \mu \mathrm{l}$ of growth medium. A $10 \mu \mathrm{l}$ aliquot of the individual test sample was then added to the cell suspension in a well, and the mixture was incubated for $48 \mathrm{~h}$ at $37^{\circ} \mathrm{C}$. After adding the MTT solution $(10 \mu l)$ to each well, cells were kept for another $4 \mathrm{~h}$ at $37^{\circ} \mathrm{C}$ for detection of cytotoxicity. Black precipitate of formazan generated by cellular reduction of MTT was separated from the overlying medium by pipetting out the medium and then dissolved with $150 \mu \mathrm{l}$ of isopropanol containing $0.04 \mathrm{~N} \mathrm{HCl}$. The absorbance of the formazan solution was read with a microplate reader at $490 \mathrm{~nm}$. Three parallel tests were run. Control experiments were run without adding the test samples. Cytotoxicity was evaluated as the decrease of formation of formazan. ${ }^{12}$

\section{Results and Discussion}

The results of mouse bioassays and fluorometric HPLC analysis are shown in Table 1. Of the eleven samples tested, three showed toxicity levels above $0.5 \mathrm{MU} / \mathrm{g}$, indicating their inadequacy as food. Occurrence of $\mathrm{OA}$ in these three samples was confirmed by HPLC analysis on two columns. Neither DTX1 nor PTX6 was detected by HPLC analysis. Neutral fractions obtained by treatment over alumina did not show any mouse lethality, ruling out the presence of PTXs 1 through 4. A significant discrepancy was observed in the Rimini sample between toxicity levels determined by mouse assay and by HPLC analysis. Mice injected with an acidic fraction of the Rimini sample quickly developed signs of illness and died within $4 \mathrm{~h}$ with severe convulsions before death. Although these signs resembled those of YTX, TLC comparison ruled out the presence of this toxin, and suggested the occurrence of a new toxin or toxins. Purification by reversed-phase HPLC showed four peaks eluting prior to that of $\mathrm{OA}$, indicating their higher polarity than OA (Fig. 3). All four fractions were cytotoxic against P388 murine leukemia cells, having $\mathrm{IC}_{50 \mathrm{~s}}<0.2 \mu \mathrm{g} / \mathrm{m} \mathrm{l}$. Formazan formation was reduced to approximately one third of that of the control (Fig. 4). Because of the extremely small amounts available, further characterization of the toxins was unsuccessful. They did not give fluorescent esters by the treatment with ADAM. Thus, the

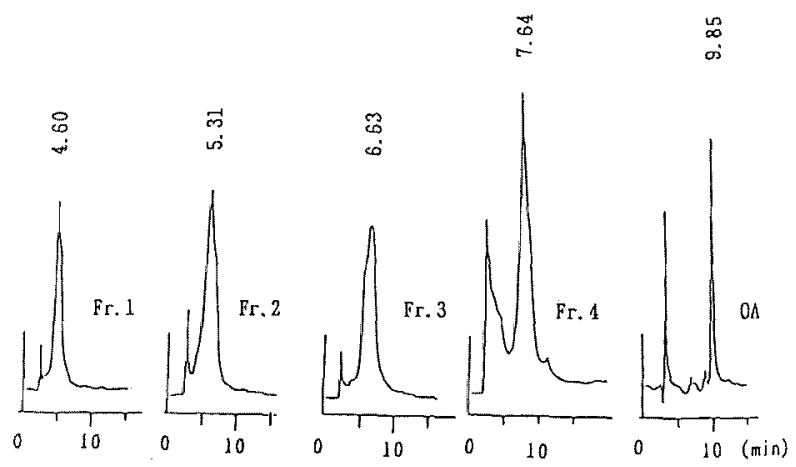

Fig. 3. Chromatograms of four cytotoxic fractions (1-4) from the Rimini sample and reference okadaic acid (OA).

Column, Develosil ODS-5 $(4.6 \times 250 \mathrm{~mm})$; mobile phase, MeOH-

$0.1 \% \mathrm{HOAC}(8: 2)$; flow rate, $1.0 \mathrm{ml} / \mathrm{min}$; monitor, $205 \mathrm{~nm}$. 


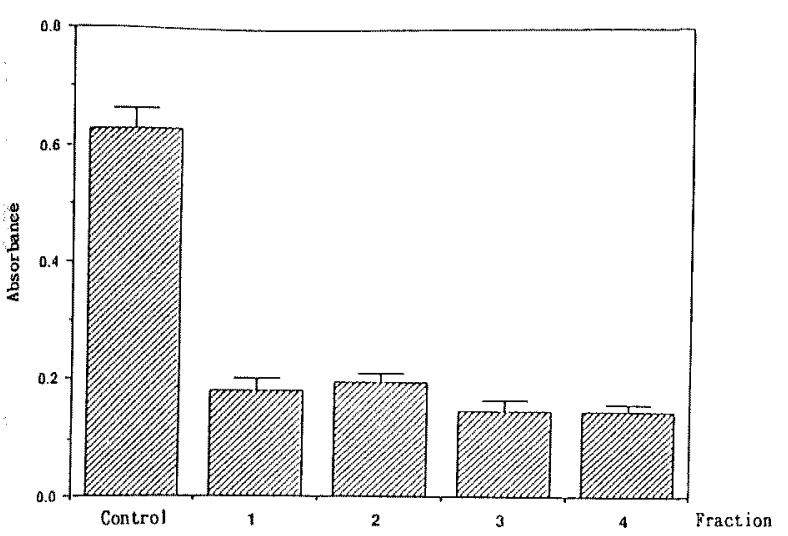

Fig. 4. Cytotoxicity of four fractions from the Rimini sample Test solution was applied to cells in the presence of MTT, and cytotoxicity was observed as the decrease of formazan formation. Tests were run in triplicate.

possibility of contaminant $\mathrm{OA}$ in these fractions was ruled out.

The present study confirmed that OA is the major DS-toxin in mussels from the Adriatic Sea. This result agrees with our previous finding that $\mathrm{OA}$ is the principal toxin in mussels collected from the Atlantic coast of Europe and Scandinavian waters ${ }^{13)}$ and agrees with a recent report on identification of OA in Italian mussels. ${ }^{10}$ ) This is the first time, however, to observe discrepancy between mouse assay and HPLC results and to explain the discrepancy as due to new toxins having cytotoxic activity. As $\mathrm{OA}$ and its derivatives also have potent cytotoxicity, ${ }^{4)}$ cell assay methods using MTT can be an effective means for monitoring these toxins. None of the new toxins corresponded with DTX2, a new member of DS-toxins reported to have been eluted after OA in the HPLC analysis. ${ }^{14)}$ Neither were they identical in chromatographic properties with other known members of DSP. The source and toxicological properties of these new toxins should be elucidated in future studies. Another interesting aspect of the present study is the absence of pectenotoxins in the mussels tested. Apparently, Dinophysis fortii occurring in the Adriatic Sea ${ }^{8)}$ differs from the Japanese strain which produces pectenotoxin-2, along with dinophysistoxin-1 and/or okadaic acid. ${ }^{15)}$ The cause of the intraspecies variation is an intriguing problem in the biosynthesis of polyether toxins.

\section{References}

1) B. Sundstrom, L. Elker, and E. Graneli: The global distribution of harmful effects of phytoplankton, in "Toxic Marine Phytoplankton" (ed. by E. Graneli, B. Sundstrom, L. Edler, and D. M. Anderson), Elsevier, New York, 1990, pp. 537-541.

2) T. Yasumoto, Y. Oshima, and M. Yamaguchi: Occurrence of a new type of shellfish poisoning in the Tohoku District, Nippon Suisan Gakkaishi, 44, 1249-1255 (1978).

3) T. Yasumoto, M. Murata, J.-S. Lee, and K. Torigoe: Polyether toxins produced by dinoflagellates, in "Mycotoxins and Phycotoxins ' 88 " (ed. by S. Natori, K. Hashiomoto, and U. Ueno), Elsevier, Amsterdam, 1989, pp. 375-382.

4) Y. Hamano, Y. Kinoshita, and T. Yasumoto: Enterogenicity of diarrhetic shellish toxins in intestinal models. J. Food Hyg. Soc. Japan, 27, 374-375 (1986).

5) K. Terao, E. Ito, T. Yanagi, and T. Yasumoto: Histopathological studies on experimental marine toxin poisoning. I. Ultrastructural change in the small intestine and liver of suckling mice induced by dinophysistoxin-1 and pectenotoxin-1. Toxicon, 24, 1141-1151 (1986).

6) H. Fujiki, M. Suganuma, H. Suguri, S. Yoshizawa, K. Takagi, T. Sassa, N. Uda, K. Wakamatsu, K. Yamada, T. Yasumoto, Y. Kato, N. Fusetani, K. Hashimoto, and T. Sugiura: New tumor promoters from marine sources, in "Mycotoxins and Phycotoxins ' 88 " (ed. by S. Natori, K. Hashimoto, and T. Uenos), Amsterdam, Elsevier, 1989, pp. $453-460$.

7) J. S. Lee, T. Yanagi, R. Kenma, and T. Yasumoto: Fluorometric determination of diarrhetic shellfish toxins by high performance liquid chromatography. Agric. Biol. Chem., 51, 877-881 (1987).

8) B. Sedmak and N. Fanuko: Occurrence of Dinophysis spp. and toxic shellfish in the Northern Adriatic. J. Appl. Phycol., 3, 289-294 (1991).

9) A. Tubaro, S. Sosa, M. Bruno, P. Margherita, B. Gucci, L. Volterra, and R. D. Loggia: Diarrhoeic shellfish toxins in Adriatic Sea mussels evaluated by an ELISA method. Toxicon, 30, 673-676 (1992).

10) E. Fattorusso, P. Ciminiello, V. Costantina, S. Magno, A. Mangoni, A. Milandri, R. Poletti, M. Pompei, and R. Viviani: Okadaic acid in mussels of Adriatic Sea. Mar. Poll. Bull., 24, 234-237 (1992).

11) J.-S. Lee, K. Tangen, E. Dahl, P. Hovgaard, and T. Yasumoto: Diarrhetic shellfish toxins in Norwegian mussels. Nippon Suisan Gakkaishi, 54, 1953-1957 (1988).

12) D. A. Scudiero, R. H. Shoemaker, K. D. Paull, A. Monks, S. Tierney, T. H. Nofziger, M. J. Currens, D. Seniff, and M. R. Boyd: Evaluation of a solube tetrazolium/formazan assay for cell growth and drug sensitivity in culture using human and other tumor cell lines. Cancer Res., 48, 4827-4833 (1988).

13) M. Kumagai, T. Yanagi, M. Murata, T. Yasumoto, M. Kat, P. Lassus, and $\mathbf{J}$. A. Rodriguez-Vazquez: Okadaic acid as the causative toxin of diarrhetic shellftsh poisoning in Europe. Agric. Biol. Chem., 50, 2853-2857 (1986).

14) T. Hu, J. Doyle, D. Jackson, J. Marr, E. Nixon, S. Pleasance, M. A. Quilliam, J. A. Walter, and J. L. C. Wright: Isolation of a new diarrhetic shellfish poison from Irish mussels. J. Chem. Soc., Chem. Commun., 39-41 (1992).

15) J.-S. Lee, T. Igarashi, S. Fraga, E. Dahl, P. Hovgaard, and T. Yasumoto: Determination of diarrhetic shellfish toxins in various dinoflagellate species. J. Appl. Phycol., 1, 147-152 (1989). 